\title{
RESPOSTAS DO HÍBRIDO DE SORGO-SUDÃO ÀS ADUBAÇÕES NITROGENADA E POTÁSSICA: CARACTERÍSTICAS ESTRUTURAIS E PRODUTIVAS ${ }^{1}$
}

\author{
Nitrogen and potassium fertilization effects on a sorghum hybrid: \\ structural and yield traits
}

\author{
Flávia Fernanda Simili ${ }^{2}$, Carlos Augusto de Miranda Gomide ${ }^{3}$, Andréia Luciane Moreira ${ }^{4}$, \\ Ricardo Andrade Reis ${ }^{5}$, Maria Lúcia Pereira Lima ${ }^{2}$, Claudia Cristina Paro de Paz $^{2}$
}

\begin{abstract}
RESUMO
A pesquisa foi instalada no Setor de Forragicultura da FCAV/UNESP-Jaboticabal, para avaliar o híbrido de sorgo-sudão AG $2501 \mathrm{C}$ no outono e inverno. O manejo da pastagem foi conduzido, simulando o sistema de lotação intermitente. O experimento foi desenvolvido de março a setembro de 2002. A forrageira foi submetida a nove tratamentos: três doses de N (100, $200 \mathrm{e} 300 \mathrm{~kg} / \mathrm{ha}) \mathrm{e}$ três doses de $\mathrm{K}\left(0,80\right.$ e $160 \mathrm{~kg} / \mathrm{ha}$ de $\left.\mathrm{K}_{2} \mathrm{O}\right)$, em delineamento experimental de blocos casualizados com três repetições em esquema de parcelas subdivididas. As características estudadas foram massas, secas, inicial de planta inteira, folha e colmo e massa seca residual; relação lâmina/colmo; índice de área foliar (IAF); interceptação da radiação fotossinteticamente ativa (RFA) e coeficiente de extinção luminosa. Os tratamentos não influenciaram a massa seca inicial (MSI) e residual (MSR) da planta inteira, folha e colmo e massa seca residual. Os resultados médios para MSI, MSR, folha e colmo foram 2801,2; 964,7; 1462,8 e 1085,2 kg/ha de MS, por ciclo de pastejo, respectivamente. Houve redução da relação lâmina/colmo e da porcentagem de folhas, enquanto a porcentagem de colmos aumentou. Houve interação entre N e K para IAF, interceptação de luz e coeficiente de extinção.
\end{abstract}

Termos para indexação : Gramíneas anuais de verão, índice de área foliar, interceptação de luz, Sorghum bicolor x Sorghum sudanense.

\section{ABSTRACT}

This research was carried out in the Forage Section of FCAV/UNESP-Jaboticabal, to evaluate hybrid sorghum AG 2501C (Sorghum bicolor $\mathrm{x}$ Sorghum sudanense) during autumn/winter. Pasture management was accomplished by a simulation of intermittent stocking. The experiment was developed from March to September of 2002. The forage was submitted to nine treatments: three doses of $\mathrm{N}(100,200$, and $300 \mathrm{~kg} / \mathrm{ha})$ and three doses of $\mathrm{K}\left(0,80\right.$, and $160 \mathrm{~kg} / \mathrm{ha}$ of $\left.\mathrm{K}_{2} \mathrm{O}\right)$ in a randomized block design with three replications in a split plot scheme. Characteristics including forage mass before grazing (FMBG), after grazing (residual), leaf and stem, leaf/stem ratio, leaf area index (LAI), interception of light, and light extinction coefficient (LEC) were evaluated. No differences for FMBG, residual, leaf, and stem were found. The averages were 2801.2, 964.7, 1462.8, and 1085.2 kg/ha of DM, per grazing cycle for FMBG, residual, leaf, and stem. There was significant interaction $(\mathrm{p}<0,01)$ between $\mathrm{N}$ and $\mathrm{K}$ for LAI, interception of light, and LEC.

Index terms: Interception of light, leaf area index, Sorghum bicolor x Sorghum sudanense, tropical annual grass.

\section{(Recebido em 23 de outubro de 2006 e aporvado em 18 de fevereiro de 2008)}

\section{INTRODUÇÃo}

A utilização de gramíneas anuais de crescimento de verão no outono-inverno é uma alternativa pouco explorada para produção de forragem de alto valor nutritivo nas condições edafoclimáticas do Brasil Central. Dentre os materiais disponíveis para utilização, destacam-se os híbridos de sorgo-sudão, oriundo do cruzamento Sorghum bicolor (L.) Moench x Sorghum sudanense (Piper) Stapf.

O nitrogênio $(\mathrm{N})$ é o nutriente-chave para aumentar a produtividade das gramíneas forrageiras, sendo o principal constituinte das proteínas que participam ativamente na síntese dos compostos orgânicos que formam a estrutura vegetal. É, portanto, responsável por características imprescindíveis nas plantas, tais como tamanho da folha e do colmo, aparecimento e desenvolvimento dos perfilhos, dentre outras.

De acordo com Gomide (1973), o incremento na produção de massa seca em resposta a aplicação de $\mathrm{N}$ reflete-se por meio do aumento do número de folhas, perfilhos e posterior alongamento dos respectivos colmos.

\footnotetext{
${ }^{1}$ Parte da dissertação de mestrado defendido na Faculdade de Ciências Agrárias e Veterinárias - UNESP - Jaboticabal ${ }^{2}$ APTA/SAA - Ribeirão Preto, SP - flaviasimili@apta.sp.gov.br ${ }^{3}$ EMBRAPA - Juiz de Fora, MG 
Segundo Fribourg (1995), gramíneas anuais de verão têm apresentado respostas lineares à adubação nitrogenada até doses de $200 \mathrm{~kg} / \mathrm{ha}$.

O potássio $(\mathrm{K})$ é um nutriente de grande importância, sendo essencial para que as plantas se desenvolvam e completem seu ciclo biológico. Isso porque o K participa direta ou indiretamente de inúmeros processos bioquímicos envolvidos com o metabolismo de carboidratos, como a fotossíntese e a respiração, e sua carência reflete-se numa baixa taxa de crescimento.

Para que seja possível explorar o potencial de produção e crescimento de uma determinada forrageira torna-se necessário conhecer suas características morfofisiológicas e estruturais.

A relação folha/colmo é uma importante característica de estrutura do relvado, principalmente em gramíneas tropicais que apresentam rápido desenvolvimento dos colmos (Stobbs, 1973; Silva et al., 1994; Corsi et al., 2001). Essa característica é capaz de condicionar o comportamento ingestivo dos animais (Stobbs, 1973) e o desempenho animal sob pastejo (Silva et al., 1994; Euclides et al., 1999).

Gomide (1973) reconhece a importância do conceito de IAF, recomendando cuidado no manejo de pastagem sob lotação rotacionada no sentido de que o gado deveria ser retirado dos piquetes antes de ocorrer uma desfolha intensa.

Neste trabalho, objetivou-se estudar os efeitos das adubações nitrogenada e potássica na produção de forragem e em algumas características estruturais do híbrido de sorgo-sudão no período de outono-inverno sob lotação intermitente.

\section{MATERIAL E MÉTODOS}

O experimento foi conduzido no Setor de Forragicultura da Faculdade de Ciências Agrárias e Veterinárias de Jaboticabal - UNESP, situado a $21^{\circ} 15^{\prime}$ de latitude $\mathrm{S}, 48^{\circ} 18^{\prime}$ de longitude $\mathrm{W}$ e altitude média de 595 metros. O solo é classificado como Latossolo vermelho distrófico de textura média (Embrapa, 1999). A análise de solo revelou os seguintes resultados: $\mathrm{pH}$ em $\mathrm{CaCl}_{2} 5,7$, matéria orgânica $23 \mathrm{~g} / \mathrm{dm}^{3}$, fósforo $(\mathrm{P})$ em resina $33 \mathrm{mg} / \mathrm{dm}^{3}$, potássio (K) 4,2 $\mathrm{mmol} / \mathrm{dm}^{3}$, Cálcio (Ca) $41 \mathrm{mmol} / \mathrm{dm}^{3}$, magnésio $(\mathrm{Mg})$ $18 \mathrm{mmol} / \mathrm{dm}^{3}$, hidrogênio mais alumínio (H+Al) $20 \mathrm{mmol} /$ $\mathrm{dm}^{3}$, capacidade de troca de cátions (CTC) $83 \mathrm{mmol} / \mathrm{dm}^{3}$; soma de bases (SB) $63,3 \mathrm{mmol} / \mathrm{dm}^{3}$ e saturação por bases (V) 76\%. Os dados metereológicos foram obtidos na Estação Agrometereológica do Departamento de Ciências Exatas, UNESP, Jaboticabal (Figura 1).

A semeadura foi realizada em linhas de plantio em 11 de março de 2002, com espaçamento de $22,5 \mathrm{~cm}$, empregando $16 \mathrm{~kg} / \mathrm{ha}$ de sementes do híbrido de sorgosudão AG 2501C. Na adubação de plantio foram utilizados $100 \mathrm{~kg} / \mathrm{ha}$ de $\mathrm{P}_{2} \mathrm{O}_{5}$ na forma de superfosfato simples. As adubações referentes aos tratamentos experimentais foram realizadas por cobertura, 20 dias após o plantio ou após os ciclos de pastejo. O híbrido de sorgo-sudão AG 2501C foi submetido a nove tratamentos dispostos em esquema fatorial $3 \times 3$, sendo três doses de adubações nitrogenada $(100,200$ e $300 \mathrm{~kg} / \mathrm{ha}$ de $\mathrm{N}$ na forma de uréia) e potássica (0, 80 e $160 \mathrm{~kg} / \mathrm{ha}$ de $\mathrm{K}_{2} \mathrm{O}$ na forma de cloreto de potássio), com três repetições.

A pastagem foi manejada simulando o sistema de lotação intermitente, com três dias de ocupação. Após 35 dias do plantio, realizou-se o $1^{\circ}$ pastejo em 19/04; o $2^{-\circ}$, o $3^{\circ}$ e o 4-pastejo ocorreram em 04/06, 25/07 e 04/09, após 46, 51 e 41 dias, respectivamente. Foram utilizadas 20 vacas da raça Holandês malhada de preto, com peso médio de 550 $\mathrm{kg}$. Os animais foram utilizados apenas como ferramenta para rebaixar a pastagem, com média de taxa de lotação de 5,0 UA/ha.

A entrada dos animais na área experimental foi determinada por meio da altura das plantas, estabelecendose como critério 1,0 a 1,2 m e a saída com altura de resíduo

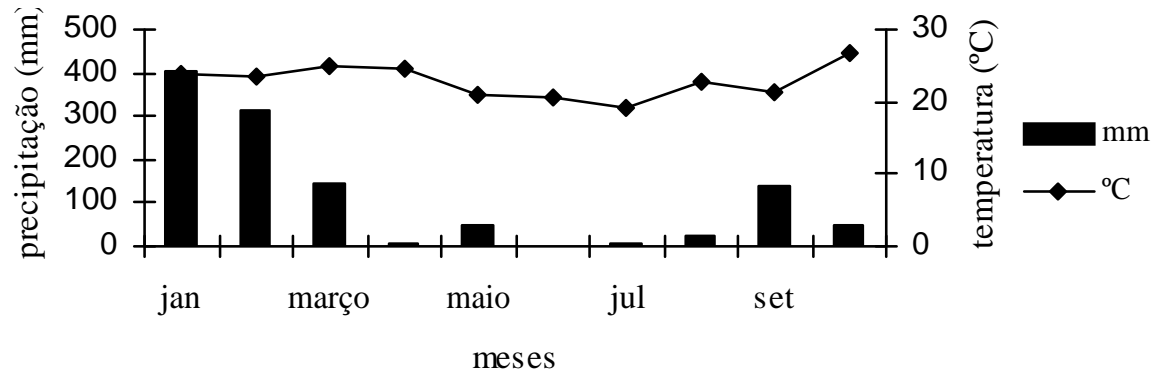

Figura 1 - Precipitação pluviométrica e temperatura média durante o período experimental. 
de 0,50 m. Foi feita irrigação a partir do $2^{\circ}$ pastejo (04/06), utilizando-se lâmina d'água de $15 \mathrm{~mm}$ semanais, totalizando $60 \mathrm{~mm}$ de precipitação mensal.

Antes e após a desfolha, pelos animais, foram estudadas as variáveis massas secas de forragens inicial e residual, assim como as de folha e colmo. As amostras foram obtidas por meio do corte das plantas rente ao solo e pesagem da forragem verde de duas amostras de $1 \mathrm{~m}^{2}$ tomadas por parcela e por ciclo de pastejo, sendo levadas à estufa de renovação e circulação forçada de ar a $60^{\circ} \mathrm{C}$ para secagem até peso constante e posterior determinação da matéria seca (MS). A relação lâmina/colmo foi estimada por meio da separação e pesagem da folha cortada na altura da lígula, permanecendo a bainha aderida ao colmo, que também foi seco. A relação lâmina/colmo foi determinada dividindose o peso seco das lâminas pelo peso seco dos colmos.

Durante a recuperação pós-pastejo do híbrido de sorgo-sudão AG 2501C, foram medidas semanalmente as variáveis estruturais do dossel: índice de área foliar (IAF), interceptação da radiação fotossinteticamente ativa (RFA ou interceptação de luz) e o coeficiente de extinção luminosa. O IAF e a interceptação de luz foram determinadas por meio de leituras simultâneas, utilizando-se um sistema de análise de dossel - SunScan (Delta -T, Cambridge, Inglaterra). O coeficiente de extinção luminosa foi calculado a partir dos dados de IAF e interceptação de luz, conforme descrito por Sheehy \& Cooper (1973), como sendo Coeficiente de extinção $=\left[\log _{\mathrm{e}}\left(\mathrm{I} / \mathrm{I}_{0}\right)\right] / \mathrm{IAF}$, onde $\mathrm{I}$ e $\mathrm{I}_{0}$ são valores de irradiância abaixo e acima da folhagem, respectivamente.

O delineamento experimental utilizado foi blocos ao acaso, com três repetições, no esquema de parcelas subdivididas (repetição no tempo) para as variáveis massas secas de forragens inicial e residual, colmo e folha, considerando-se os ciclos de pastejo como subparcelas. As variáveis IAF, interceptação de luz e coeficiente de extinção foram analisadas como parcelas subsubdivididas. Nas parcelas, foram avaliados os tratamentos de adubações; nas subparcelas, os ciclos de pastejo e nas subsubparcelas, as semanas de crescimento do sorgosudão. A área experimental foi de $4.374 \mathrm{~m}^{2}$, sendo que cada parcela de $9 \mathrm{~m} \mathrm{x} 18 \mathrm{~m}$, portanto, $162 \mathrm{~m}^{2}$, representou um tratamento, totalizando 27 parcelas experimentais. Os dados experimentais foram submetidos à análise estatística pelo PROC GLM (SAS Institute, 2003).

\section{RESULTADOS E DISCUSSÃO}

As adubações nitrogenada e potássica não influenciaram $(\mathrm{p}>0,05)$ a produção de massa seca, inicial e residual, das plantas inteiras, assim como também não houve influência $(p>0,05)$ sobre as produções de colmos e folhas do híbrido de sorgo-sudão AG 2501C, como pode ser observado na Tabela 1 . Porém, a adubação nitrogenada proporcionou aumento de $10,9 \%$ de massa seca inicial e de $16,15 \%$ de colmo, havendo reduções $(\mathrm{p}<0,05)$ da relação lâmina/colmo e da porcentagem de folhas e elevação da porcentagem de colmos. A interação entre os tratamentos não foi significativa $(\mathrm{p}>0,05)$.

Tem-se observado, em experimentos referentes às adubações nitrogenada e potássica, resposta positiva das gramíneas, conforme se aumenta a quantidade dos nutrientes aplicados, até um determinado limite. De acordo com Heringer \& Moojen (2002), trabalhando com o milheto (Pennisetum americanum (L.) Leeke) na região sul no período de dezembro de 1993 a abril de 1994, a produção de forragem variou de 8,86 a 17,4 t/ha de massa seca, sendo que o máximo de produção foi obtido com $464 \mathrm{~kg} / \mathrm{ha}$ de N, correspondendo a 17,4 t/ha de massa seca.

Lupatini et al. (1996) avaliaram o milheto sob pastejo na região sul e observaram que a utilização de doses crescentes de $\mathrm{N}(0,150$ e $300 \mathrm{~kg} / \mathrm{ha})$ aumentou a produção de massa seca $(6,2 ; 12,17$ e $15,6 \mathrm{t} / \mathrm{ha}$, respectivamente), sendo que a eficiência de uso do $\mathrm{N}$ foi de 39,3 e $31,0 \mathrm{~kg}$ de massa seca produzida por $\mathrm{kg}$ de $\mathrm{N}$ aplicado para 150 e 300 $\mathrm{kg} / \mathrm{ha}$ de $\mathrm{N}$, respectivamente. $\mathrm{Na}$ ocasião, a temperatura média da região foi de $19,2^{\circ} \mathrm{C}$.

Medeiros et al. (1979), estudando o efeito da adubação nitrogenada, verificaram aumento no rendimento forrageiro do híbrido de sorgo-sudão, sendo que a dose que proporcionou o máximo rendimento $(5,8 \mathrm{t} / \mathrm{ha}$, média de 3 cortes) foi de $253 \mathrm{~kg} / \mathrm{ha}$ de $\mathrm{N}$ parcelada em 3 aplicações.

No presente trabalho, os resultados referentes à massa seca de forragem produzida não estão de acordo com as referências citadas pois a gramínea estudada não respondeu às doses elevadas de adubo utilizado. No entanto, o período em que foi efetuado o estudo foi caracterizado pelas baixas temperatura e precipitação, como pode ser visto na Figura 1, apesar da irrigação aplicada após o segundo ciclo de pastejo. Além disso, o local onde o experimento foi conduzido apresentava alta fertilidade do solo, com excesso de K, e o sorgo não é dos mais exigentes em fertilidade do solo. Somente a porcentagem de material morto foi influenciada pelas doses de $\mathrm{K}$, sendo mais alta sob $80 \mathrm{~kg} / \mathrm{ha}$ de $\mathrm{K}_{2} \mathrm{O}$, que não diferiu de $160 \mathrm{~kg} / \mathrm{ha}$ de $\mathrm{K}_{2} \mathrm{O}$.

A intensidade dos efeitos positivos do $\mathrm{N}$ é frequentemente alterada por fatores ambientais, especialmente a disponibilidade de água no solo. Doss et al. (1964) demonstraram que o rendimento de MS do sorgo Sart foi aumentado pelo N ou pela irrigação. No entanto, os máximos rendimentos somente foram obtidos quando os dois fatores estavam associados. 
Tabela 1 - Massas secas de forragens inicial e residual, colmo e folha; relação lâmina/colmo e porcentagens de colmo, folha, material morto e inflorescência do híbrido de sorgo-sudão AG 2501C submetido às adubações nitrogenada e potássica.

\begin{tabular}{|c|c|c|c|c|}
\hline & \multicolumn{4}{|c|}{ Doses de N (kg/ha) } \\
\hline & 100 & 200 & 300 & $\mathrm{p}$ \\
\hline Massa seca inicial (kg/ha de MS) & 2713,7 & 2680,2 & 3009,7 & 0,190 \\
\hline Massa seca residual (kg/ha de MS) & 949,2 & 943,5 & 1001,4 & 0,730 \\
\hline Colmo (kg/ha de MS) & 1369,4 & 1428,4 & 1590,6 & 0,190 \\
\hline Folha (kg/ha de MS) & 1120,0 & 1026,0 & 1109,7 & 0,540 \\
\hline Relação lâmina/colmo & $0,88^{\mathrm{a}}$ & $0,77^{\mathrm{ab}}$ & $0,72^{\mathrm{b}}$ & 0,039 \\
\hline Colmo $(\%)$ & $49,9^{\mathrm{b}}$ & $52,4^{\mathrm{ab}}$ & $54,4^{\mathrm{a}}$ & 0,030 \\
\hline Folha $(\%)$ & $41,2^{\mathrm{a}}$ & $37,7^{\mathrm{ab}}$ & $35,7^{\mathrm{b}}$ & 0,005 \\
\hline Material morto (\%) & 2,5 & 2,3 & 2,2 & 0,450 \\
\hline \multirow[t]{3}{*}{ Inflorescência $(\%)$} & 6,42 & 7,4 & 7,7 & 0,650 \\
\hline & \multicolumn{4}{|c|}{ Doses de $\mathrm{K}_{2} \mathrm{O}(\mathrm{kg} / \mathrm{ha})$} \\
\hline & 0 & 80 & 160 & $\mathrm{p}$ \\
\hline Massa seca inicial (kg/ha de MS) & 2769,1 & 2778,9 & 2855,6 & 0,880 \\
\hline Massa seca residual (kg/ha de MS) & 946,2 & 963,6 & 984,4 & 0,890 \\
\hline Colmo (kg/ha de MS) & 1441,5 & 1449,6 & 1497,3 & 0,880 \\
\hline Folha (kg/ha de MS) & 1063,7 & 1104,8 & 1082,3 & 0,920 \\
\hline Relação lâmina/colmo & 0,76 & 0,79 & 0,82 & 0,680 \\
\hline Colmo $(\%)$ & 51,8 & 53,0 & 51,8 & 0,670 \\
\hline Folha $(\%)$ & 38,9 & 37,7 & 37,9 & 0,710 \\
\hline Material morto (\%) & $1,9^{\mathrm{bc}}$ & $2,8^{\mathrm{a}}$ & $2,3^{\mathrm{ab}}$ & 0,009 \\
\hline Inflorescência (\%) & 7,5 & 6,2 & 7,8 & 0,520 \\
\hline
\end{tabular}

Letras iguais nas linhas não diferem estatisticamente pelo teste de Tukey ( $p>0,05)$.

Um outro fator que pode estar relacionado com a baixa produção de massa seca é a utilização de uréia como adubo nitrogenado, em virtude de sua baixa eficiência. De acordo com estudos realizados por Cantarella et al. (2001), a uréia $\left[\left(\mathrm{NH}_{2}\right)_{2} \mathrm{CO}\right]$ rapidamente se transforma em amônia $\left(\mathrm{NH}_{3}\right)$, que se volatiliza. De acordo com estudos realizados por Cantarella et al. (2001), as perdas por volatilização de $\mathrm{NH}_{3}$ em cinco adubações anuais em pastagem de capimcoastcross (Cynodon dactylon (L.) Pers) variaram de 15 a $40 \%$ e de 14 a $31 \%$ do $\mathrm{N}$ aplicado na forma de uréia, em 19981999 e 1999-2000, respectivamente, enquanto as perdas utilizando-se o nitrato de amônio foi menor que $1 \%$ nos dois anos de observação. Segundo esses autores, a magnitude das perdas de $\mathrm{NH}_{3}$ por volatilização depende das condições climáticas, especialmente da umidade do solo.

Houve efeito dos ciclos de pastejo $(\mathrm{p}<0,01)$ nas produções de massas secas de forragens, colmos e folhas (Tabela 2). O segundo ciclo de pastejo foi o mais prejudicado pelos fatores climáticos mencionados anteriormente. $\mathrm{O}$ aumento das massas secas inicial e residual é explicado pelo acúmulo de colmo e seu alongamento com o decorrer dos pastejos. Além disso, o material não consumido pelos animais também contribui para este acréscimo.

A relação lâmina/colmo só diferiu estatisticamente $(\mathrm{p}<0,01)$ no $2^{\circ}$ ciclo, isto porque as quantidades de MS dos colmos e das folhas aumentaram. Não houve diferença ( $>00,05)$ para porcentagem de colmos, provavelmente, porque houve aparecimento das inflorescências e com isso a porcentagem de folhas diminuiu.

A queda na relação lâmina/colmo sinaliza redução no valor nutritivo da forragem disponível, bem como prejuízo para a eficiência de pastejo animal. Sollenberger \& Burns (2001) argumentaram que, em se tratando de espécies de gramíneas tropicais, características como porcentagem de folhas, massa foliar e a acessibilidade das folhas ao animal são de grande importância para o consumo. 
Com relação às características estruturais estudadas durante o período experimental, houve interação entre o $\mathrm{N}$ e o K para o IAF, a interceptação de luz e para o coeficiente de extinção como pode ser visto na Figura 2.

A interceptação de luz não alcançou os valores preconizados pela literatura, ou seja, 95\% (Watson, 1958; Brown \& Blaser, 1968) como sendo o momento certo de entrada dos animais. O IAF médio foi 2,54, com interceptação média de $77 \%$. Os valores referentes ao coeficiente de extinção foram em torno de 0,70 e está relacionado à quantidade de luz perdida no perfil do dossel, de modo que, quanto mais próximo de um, menor é a perda de luz. Segundo Siddique et al. (1989) e Yunusa et al. (1993), maiores valores de coeficiente de extinção podem ser atribuídos à distribuição mais uniforme da área foliar e às folhas das plantas mais planas (ângulo foliar próximo de $90^{\circ}$ ).

A interação entre semana e ciclo de pastejo foi significativa $(p<0,001)$ para IAF e Interceptação de luz, no entanto, não houve efeito das adubações nitrogenada e potássica, enquanto para coeficiente de extinção a interação entre semana e ciclo de pastejo foi significativa $(\mathrm{p}<0,001)$ e houve efeito dos tratamentos (Figura 3).

Tabela 2 - Massas secas de forragens inicial e residual, colmo e folha; relação lâmina/colmo e porcentagens de colmo, folha, material morto e inflorescência do híbrido de sorgo-sudão AG 2501C nos ciclos de pastejo.

\begin{tabular}{lccccc}
\hline & \multicolumn{5}{c}{ Ciclos de pastejo } \\
\cline { 2 - 5 } & $19 / 04$ & $04 / 06$ & $25 / 07$ & $04 / 09$ & $\mathrm{p}$ \\
\hline Massa seca inicial (kg/ha de MS) & $2411,6^{\mathrm{cb}}$ & $2092,0^{\text {cd }}$ & $2895,4^{\mathrm{b}}$ & $3805,9^{\mathrm{a}}$ & 0,0001 \\
Massa seca residual (kg/ha de MS) & $417,0^{\mathrm{d}}$ & $709,6^{\mathrm{c}}$ & $893,1^{\mathrm{b}}$ & $1839,2^{\mathrm{a}}$ & 0,0001 \\
Colmo (kg/ha de MS) & $1296,8^{\mathrm{bc}}$ & $1086,8^{\mathrm{c}}$ & $1428,5^{\mathrm{b}}$ & $2039,0^{\mathrm{a}}$ & 0,0001 \\
Folha (kg/ha de MS) & $1114,7^{\mathrm{b}}$ & $561,7^{\mathrm{c}}$ & $1187,2^{\mathrm{b}}$ & $1477,4^{\mathrm{a}}$ & 0,0001 \\
Relação lâmina/colmo & $0,88^{\mathrm{a}}$ & $0,57^{\mathrm{b}}$ & $0,93^{\mathrm{a}}$ & $0,80^{\mathrm{a}}$ & 0,0001 \\
Colmo (\%) & 53,62 & 52,67 & 49,26 & 53,36 & 0,14 \\
Folha (\%) & $46,37^{\mathrm{a}}$ & $24,95^{\mathrm{c}}$ & $41,61^{\mathrm{ab}}$ & $39,91^{\mathrm{b}}$ & 0,0001 \\
Material morto (\%)* & 0 & 9,37 & 0 & 0,04 & - \\
Inflorescência (\%)** & 0 & $12,96^{\mathrm{a}}$ & $8,94^{\mathrm{b}}$ & $6,80^{\mathrm{b}}$ & 0,0001 \\
\hline
\end{tabular}

Letras iguais nas linhas não diferem estatisticamente pelo teste de Tukey ( $p>0,05)$.

*Dados não comparados pela análise estatística. **Foram comparados apenas os três últimos ciclos de pastejo.
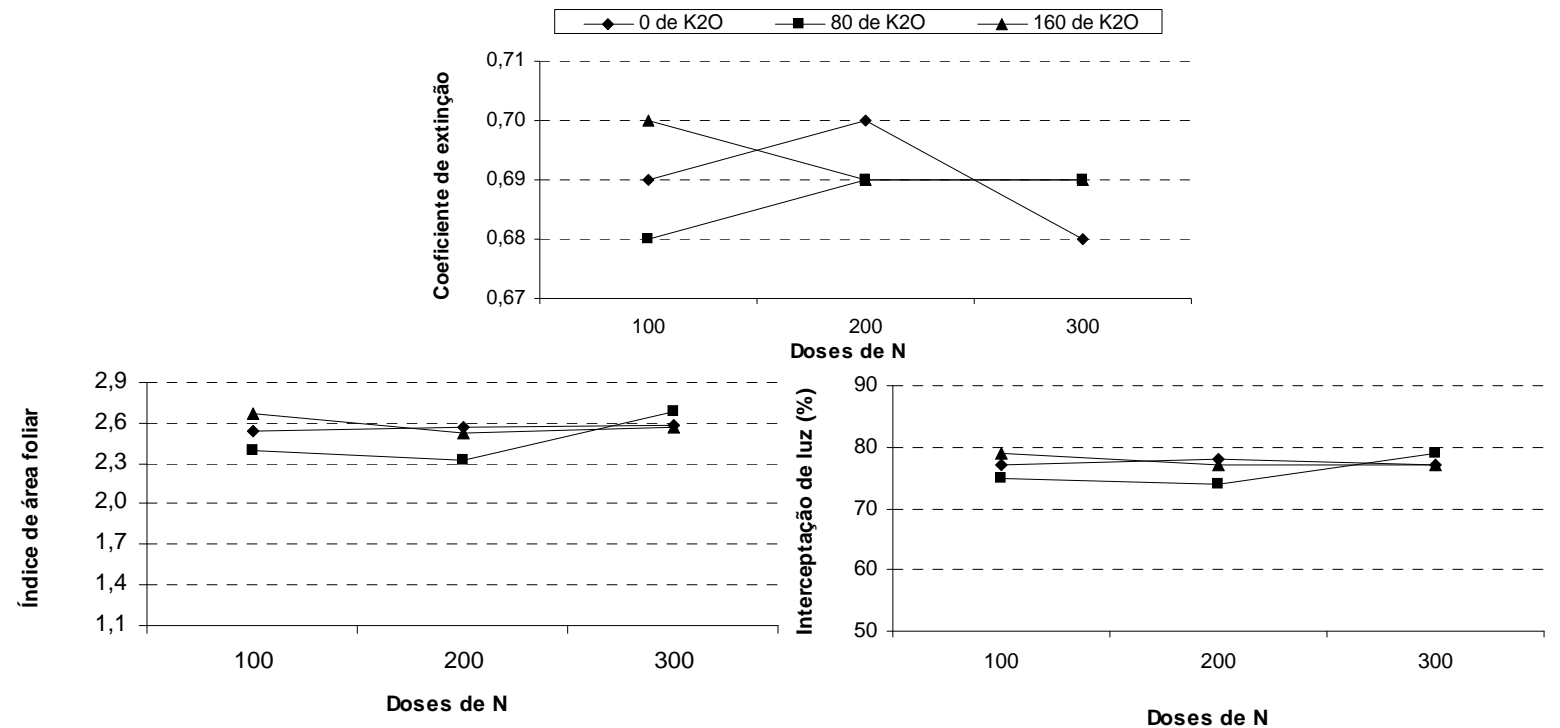

Figura 2 - Coeficiente de extinção, Índice de área foliar e Interceptação de luz para interação nitrogênio e potássio. 

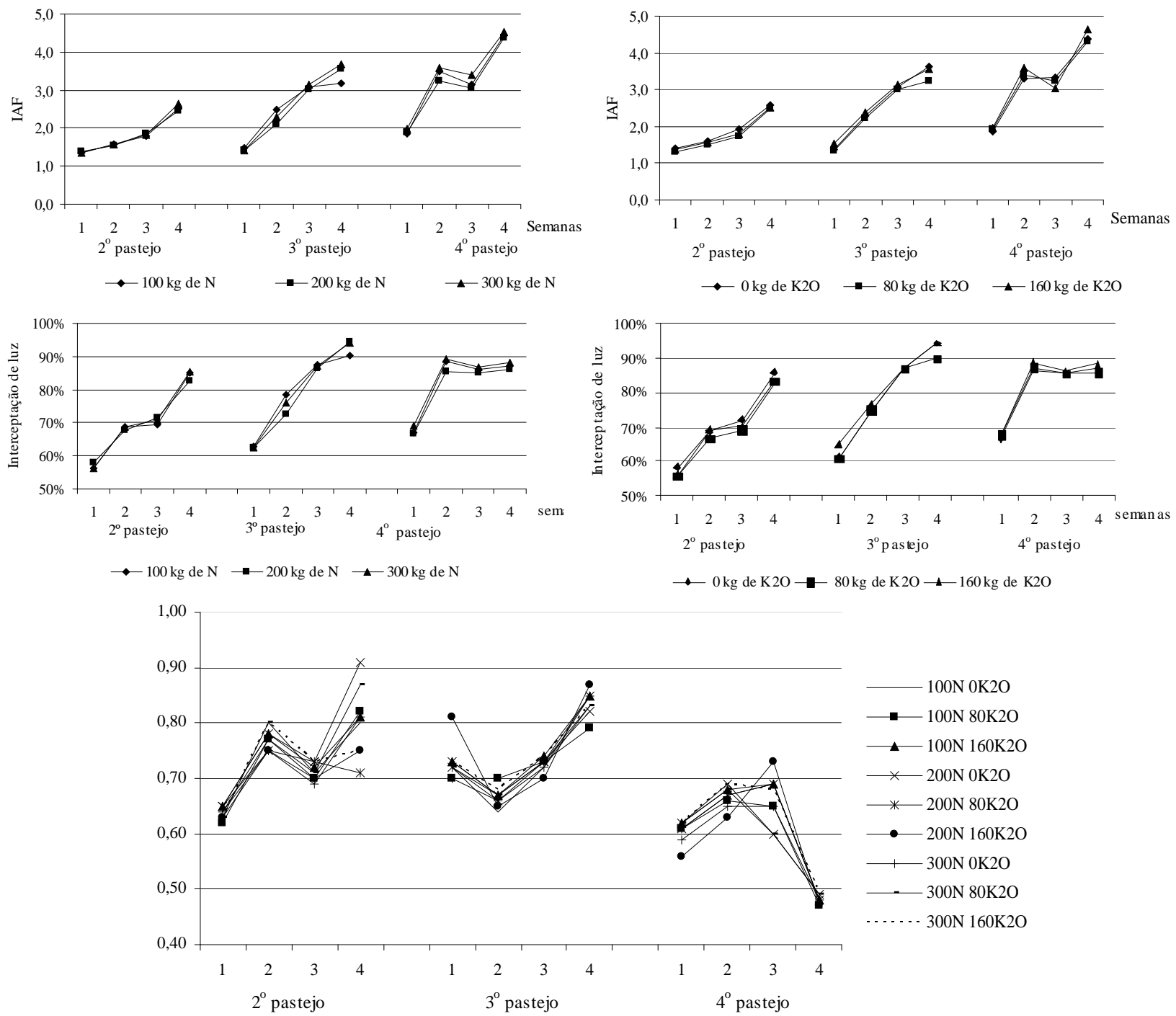

Figura 3 - Interação significativa entre semanas, ciclos de pastejo e adubações nitrogenada (N) e potássica (K) para índice de área foliar (IAF), interceptação de luz e coeficiente de extinção luminosa.

As formas como o IAF e a interceptação de luz das plantas que responderam às adubações nitrogenada e potássica foram semelhantes para as semanas e ciclos de pastejo, evidenciando a recuperação da pastagem de forma rápida. Observa-se que para o $2^{\circ}$ pastejo $(04 / 06)$ a interceptação e o IAF foram mais baixos, enquanto o coeficiente de extinção foi mais alto em decorrência da escassez de chuvas e às baixas temperaturas no período. A baixa relação lâmina/colmo (Tabela 2) nesse período pode explicar esses resultados. No $4^{\circ}$ pastejo (04/09) os valores de IAF são maiores, porém, com coeficientes de extinção luminosa mais baixos (Figura 3). Esses valores significam que a estrutura do dossel apresenta folhas mais planas e, por isso, há aumento na interceptação de luz e, consequentemente, no IAF, evidenciando uma mudança na estrutura do dossel.

A variação nos valores do coeficiente de extinção sugere alterações na arquitetura das plantas e do dossel relacionadas à época do ano, estádio fisiológico das plantas, cultivar e regime de desfolha. No entanto, são necessários mais estudos com a finalidade de entendimento dos padrões de resposta e estabelecimento das relações de causa e efeito, para que possam ser 
estabelecidos parâmetros de manejo do pastejo, visando a assegurar a produtividade e longevidade das pastagens cultivadas.

\section{CONCLUSÕES}

A adubação nitrogenada de $100 \mathrm{~kg} /$ ha foi suficiente para a produção de massa seca de forragem do híbrido de sorgo-sudão AG $2501 \mathrm{C}$ de 11,2 t/ha em quatro ciclos de pastejo, considerando a alta fertilidade do solo e a baixa precipitação pluviométrica no período do outono-inverno, sem haver mudanças nas características estruturais do dossel.

\section{REFERÊNCIAS BIBLIOGRÁFICAS}

BROWN, R.H.; BLASER, R.E. Leaf area index in pasture growth. Herbage Abstracts, Walingford, v.38, n.1, p.1-9, 1968.

CANTARELLA, H.; CORRÊA, L.A.; PRIMAVESI, A.C.; PRIMAVESI, O.; FREITAS, A.R.; SILVA, A.G. Perdas diárias de amônia por volatilização, de duas fontes de adubo nitrogenado aplicadas na superfície de pastagem de capim Coastcross (Cynodon dactylon cv. Coastcross). In: REUNIÃO ANUAL DA SOCIEDADE BRASILEIRA DE ZOOTECNIA, 38., 2001, Piracicaba. Anais... Piracicaba: SBZ, 2001. p.330331.

CORSI, M.; MARTHA JUNIOR, G.B.; NASCIMENTO JUNIOR, D.; BALSALOBRE, M.A.A. Impact of grazing management on productivity of tropical grassland. In: INTERNATIONAL GRASSLAND CONGRESS, 19., 2001, São Pedro. Proceedings... São Pedro, 2001. p.801806.

DOSS, B.D.; ASHLEY, D.A.; BENNETT, O.L.; PATTERSON, R.M.; ENSMINGER, L.E. Yield, nitrogen content and water use of Sart sorghum. Agronomy Journal, Madison, v.56, n.6, p.589-592, 1964.

\section{EMPRESA BRASILEIRA DE PESQUISA}

AGROPECUÁRIA. Centro Nacional de Pesquisa de Solos. Sistema brasileiro de classificação de solos. Brasília, 1999. 412p.

EUCLIDES, V.P.B. et al. Consumo voluntário de forragem de três cultivares de Panicum maximum sob pastejo. Revista Brasileira de Zootecnia, Viçosa, v.28, n.6, p.1177-1185, 1999.
FRIBOURG, A.H. Summer annual grasses. In: BARNES, F.R. (Ed.). Forages. 5.ed. Ames: Iowa State University, 1995. p.463-472.

GOMIDE, J.A. Fisiologia e manejo de plantas forrageiras. Revista da Sociedade Brasileira de Zootecnia, Viçosa, v.2, n.1, p.17-26, 1973.

HERINGER, I.; MOOJEN, E.L. Potencial produtivo, alterações da estrutura e qualidade da pastagem de milheto submetida a diferentes níveis de nitrogênio. Revista Brasileira de Zootecnia, Viçosa, v.31, n.2, p.875882, 2002. Suplemento.

LUPATINI, G.C.; MOOJEN, E.L.; RESTLE, J.; SILVA, J.H.S. Resposta do milheto (Pennisetum americanum) sob pastejo à adubação nitrogenada. Pesquisa Agropecuária Brasileira, Brasília, v.31, n.10, p.715-720, 1996.

MEDEIROS, R.B.; SAIBRO, J.C.; BARRETO, I.L. Efeito do nitrogênio e da população de plantas no rendimento e qualidade do sorgo sordan (Sorghum bicolor (L.) Moench $x$ Sorghum sudanense (Piper) Stapf). Revista da Sociedade Brasileira de Zootecnia, Viçosa, v.8, n.1, p.7587, 1979.

SAS INSTITUTE. User's guide: statistics. Cary, 2003. 965p.

SHEEHY, J.E.; COOPER, J.P. Light interception, photosynthetic activity, and crop growth rate in canopies of six temperate forage grasses. Journal of Applied Ecology, Oxford, v.10, n.1, p.239-250, 1973.

SIDDIQUE, K.H.M.; BELFORD, R.K.; PERRY, M.W.; TENNANT, D. Growth, development and light interception of old and modern wheat cultivars in a Mediterranean-type environment. Australian Journal of Agricultural Research, Collingwood, v.40, n.1, p.473487, 1989.

SILVA, D.S.; GOMIDE, J.A.; FONTES, C.A.A.; QUEIROZ, A.C. Pressão de pastejo em pastagem de capim-elefante anão: 1., estrutura e disponibilidade de pasto. Revista da Sociedade Brasileira de Zootecnia, Viçosa, v.23, n.2, p.249-257, 1994. 
SOLLENBERGER, L.E.; BURNS, J.C. Canopy characteristics ingestive behavior and herbage intake in cultivated tropical grassland. In: INTERNATIONAL GRASSLAND CONGRESS, 19., 2001, São Pedro.Proceedings... São Pedro, 2001.p.321-327.

STOBBS, T.H. The effect of plant structure on the intake of tropical pastures: 1., variation in the bite size of grazing cattle. Australian Journal of Agriculture Research, Collingwood, v.24, p.809-819, 1973.
WATSON, D.J. The dependence of net assimilation on leaf area index. Annals of Botany, London, v.22, n.85, p.37-54, 1958.

YUNUSA, I.A.M. et al. Effect of canopy structure on efficiency of radiation, interception and use in spring wheat cultivars during pre-anthesis period in a Mediterranean-type environment. Field Crops Research, Wallingford, v.35, n.2, p.113-122, 1993. 